\title{
INFORMATION SYSTEMS RESEARCH AS DESIGN: Identity, Process, and Narrative
}

\author{
Richard J. Boland, Jr. \\ Kalle Lyytinen \\ Case Western Reserve University
}

\begin{abstract}
Information systems research has moved beyond the antagonistic dualisms that dominated its discourse over the last 20 years. Our community is now largely inclusive of diverse research traditions, and without a strong dogma. But it is also experiencing an identity crisis. Scholars are asking what the information systems field is or should be, and where it is going or should go. In this paper, we argue that such questions, although understandable as sense-making devices, are fundamentally misdirected because they ask about the things that should be part of our identity rather than the process through which we should construct it. As an alternative to this search for identity through the identification of things with which to align, we propose that a better way forward is to appreciate that researchers are designers. Viewing researchers as designers allows our identity to emerge from the unique and critical processes whereby we both reflect and shape the socio-technical world, as well as establish our position in an intellectual field. Viewing the researcher as designer leads to a questioning of the structurational processes in which researchers are, at the same time, both representing the socio-technical world (it is our medium) and shaping it through our knowledge generation (it is our outcome). Our ongoing choice of theories, methods, artifacts, and subjects becomes a fateful, existential choice of our identity, for which we should assume responsibility in the reflexive monitoring of our research conduct. The narratives we accept or resist in making our studies of information systems constitute our identity, as well as that of our field and of our subjects. The way forward is to take responsibility for maintaining a dynamic balance in the existential choices through which we bring ourselves as researchers, our research subjects, and the socio-technical world into being.
\end{abstract}




\section{INTRODUCTION}

Since the first IFIP 8.2 conference on research methods in 1984, much has changed in the field of information systems research. The 1984 conference was characterized by our fervent struggles to define the correct way of doing research and to raise the concerns of previously silenced voices in those debates. The conference and the resulting book (Mumford et al. 1985) offered a stage for alternative views on what it meant to do our research. As a result, the conference opened the gates of the information systems domain and allowed the demons and gods of continental philosophy to argue freely in its research terrain. This resulted in debates between a series of bi-polar oppositions, such as subjective versus objective, quantitative versus qualitative, positivist versus interpretivist, and critical versus noncritical modes of information systems inquiry (see, for example, Boland 1985; Jenkins 1985; Klein and Lyytinen 1985; Lyytinen and Klein 1985; Sandberg 1985). The tension of these oppositions fueled much of the research discourse in information systems for the next 10 to 15 years as reflected in the conferences that followed (Lee et al. 1997; Nissen et al. 1991).

But now, after 20 years and the turn of the millennium, these issues have become largely passé. Whereas information system scholars at the 1984 conference argued within an "either/or" dichotomy of research approaches for their favored one, we now find a more secure appreciation of a "both/and" approach that is inclusive and values the mutually informing capabilities of multiple research methods and traditions (see, for example, Baskerville and Myers 2002; Mingers 2001). This same attitude is visible in our theorizing, and we are pleased to note that the information systems field has not fallen prey to the "one best theory" mentality that can be seen in some other management disciplines (e.g., Robey 1996). Instead, the information systems field currently offers a relatively open space for multiple modes of inquiry with an almost bewildering diversity of theoretical perspectives, research topics, data collection strategies, and analysis methods.

Many of the nagging research questions that were on the intellectual agenda of our IFIP 8.2 community 20 years ago have been resolved in our theory and practice. Apres la lutte, we can say that we have won and that there is a sense of movement and accomplishment in the field. But at the same time, there is also a growing sense that we are floundering. Many of us ask: who are we as a discipline? What is the artifact and domain we are supposed to study? Are we doomed to be a second tier discipline, borrowing theory and methods from others? Are we weak because we do not have our own unique theories and methods? (For examples, see Baskerville and Myers 2002; Benbasat and Zmud 2003; Orlikowski and lacono 2001; Weber 2003.) In short, although we have progressed beyond the simple dualisms that characterized our inquiries at its dawning, we now find ourselves in another quagmire, rooted in a questioning of our identity.

In this paper we analyze the question of identity as found in our theories, our methods, and our reflexive practice. From that analysis, we propose a way forward in thinking about the intellectual mission and the future role of information systems research. We propose that doing our research be viewed as a design act in which we are located at a boundary between making representations of the socio-technical world as 
it is, and changing it into what it might be. We are always moving between describing it and constructing it, between seeing it and shaping it, between reflecting upon it, and acting upon it and thereby facing moments of existential choice in our identity construction. Our identity is made and remade through those existential choices of what we do. It is a process that we live in language, not a thing we should be or should align with. We will first discuss the concept of identity and characterize the way we see the information systems field currently addressing the question of its identity. We will then pose an alternative approach to identity construction based on viewing the researcher as a designer. This shift in approach moves us from a search for a fixed constellation of things that define our field toward a reflexive awareness of our engagements in the research process, informed by structuration theory. The role of narrative in constructing identity is then elaborated and related to our conduct of research. Finally, our unique responsibility for existential choices in our research process is highlighted with an illustration of how structuration helps us understand a current research project of our own. Finally we formulate some implications for a way forward in constructing an identity as information system researchers.

\section{INFORMATION SYSTEMS AND IDENTITY}

Identity refers to a set of characteristics that makes a thing recognizable or known. The word comes from the Latin idem, "the same." The essential attribute of identity is consistency and persistence in character: it is that which remains the same under changing circumstances. Identity as continuity over time is also one's sense of self. Within the information systems field, our research identity refers to a wide range of phenomena that display consistency, including the uniqueness of our research objects, our personal identity as researchers, the specific identities of our theories and methods, and, finally, the identities of actors and artifacts that play roles in our theories.

If there were an enduring and firm foundation for knowing about information systems, and for defining who we are as researchers and what our research object is, the question of identity and existence could not be raised with much effect. Paradoxically, then, the success we have had in moving beyond the hope for one true form of research, which has resulted in being more open to a variety of theories and methods, has paved the way for recognizing our current problematic of identity. Most of the challenges to our identity have been addressed by calling for strong core theories in our field in order to define our "own territory" (Benbasat and Weber 1996), or for a careful characterization of "IT artifacts" (Orlikowski and Iacono 2001), or for making our work more relevant and unique to the diverse set of information systems research stakeholders (Klein and Lyytinen 2003). These are all calls for actions that are expected to strengthen our identity in the sense of creating a consistency of character in our discipline. Yet, they address the quest for identity as a search for a fixed "sameness" in relationships to things like core theories, artifacts, actors, or audiences. This is another, although higher-level example, of being trapped into bipolar oppositions in defining what is proper information systems research and what is not. What we are seeking to explore instead is how something remains the same while it is continuously changing. In other words, we seek to characterize the recursive, dialectic process ofour identity construction as it takes 
place within a social field as a set of knowledge production and dissemination practices (Klein and Lyytinen 2003) that define what information system researchers are.

We believe that our field's fresh openness to the social nature of scientific knowledge has also given us the ability to approach the identity question with a heightened reflexivity on our own role in constructing the socio-technical world of information systems. Our actions as researchers of information systems engage us in their social construction and thereby involve us, knowingly or unknowingly, as designers of them. We argue, therefore, that we should approach the issue of identity through the eyes of designers who project their stories into the world (Suchman 2002) as narratives and at the same time build their identities.

As a theoretical sensitizing device, we will employ a structurational view of knowledge and social practice (Giddens 1984). It is important to note that we are applying structurational analysis to our research, not in it-i.e., we view researchers as engaged in the reflexive monitoring of their own conduct in light of the signification structures offered by structuration theory. Thus, our epistemological position applies structuration and the social constructionist imagination to our own engagement in the world as information systems researchers. We ask: how do we and how will we create identities for ourselves, our research subject, and the world we produce and reproduce through our situated practice? Consequently, it is not a question of what identity we should produce, but a question of how we will engage in the reflexive production of it through our action. In other words, we propose that our identity can be more productively thought of as a question of agency and its process of structuration. We believe that approaching our identity as a process of identity construction lays bare the existential choices we have to make in performing our research. It is these moments of choice that we should look to as we try to understand how to go forward in building an information systems research identity. How are we making ourselves and our world as we perform our research of it? How might it be made and how might we be made as part of it (by reflecting upon and constituting it at the same time)?

If there is to be some notion of "thingness" associated with our identity, it should be as an active agent, an engaged constructor of the socio-technical world-in other words, as a designer. We as information system researchers, perhaps more than other organizational scholars, should have an appreciation for the centrality of design in shaping the socio-technical world. We teach design and we study how others create designs but we are hard pressed to place ourselves into this active position in our field. Yet, design is an inescapable element of our being agents in the socio-technical world, especially if we think of design in the way that Herbert Simon developed it in his classic The Sciences of the Artificial (Simon 1996). He persistently argued that managers and organization scholars, along with other professionals, should properly be considered as designers in the engineering sense, rather than as natural scientists.

The natural scientist is concerned with the study of what is, but the engineer or the manager is concerned with creating what might be-the designed artifact. The way forward for us as information systems researchers is thus not only in perfecting our methods or theories about the world, but also in perfecting our design capabilities for and with that world. We build our identity simultaneously as researcher-scientists who reflect the socio-technical world, and as researcher-designers who exercise agency in constructing it. As information system researchers, we are like the two faced Roman god, 
Janus, living in the juncture of the present and the future, between what is and what could be, combining both of these features in our agency. Our first face sees the world as it is by looking back to the past, and by refining our theories and methods of what can be known of what is and why. Our second face sees the world as it could be by looking ahead to the future and shaping it by refining our cognitive and practical capabilities of what can be created and how. We are both scientists and designers, simultaneously, and are always located at this dynamic juncture. It is through reflexivity that we engage this duality in our professional life, and it is through reflexivity that we encounter and make our existential choices.

\section{INFORMATION SYSTEMS RESEARCH AS LANGUAGE GAMES THAT NARRATE THE WORLD}

Viewing information systems research as a two-faced process that is always looking both at the past and toward possible futures, heightens our awareness of language and language use. Our discourse within information systems research constitutes a language game (Apel 1980; Deetz 1996; Pitkin 1972; Wittgenstein 1953) in which meaning is constructed and projected into the world as we both act in it and observe it. Within this language game we build our understanding of the socio-technical world by being scientists who reflect on its form of life, and at the same time by being designers who imagine new forms of life. Our understanding of this world is echoed in our evolving concepts, terms, vocabularies, key words, models, and so forth that are used in these linguistic moves. Hence, by participating in that language game, our understanding is intimately related to our ongoing uses of language, or discourse moves (Deetz 1996), and through speech acts that narrate that world. We explain the world to ourselves and others by punctuating the "blooming, buzzing" stream of experience into sequences of events in the form of a story.

Our use of language through speech acts and the ongoing narration of experience constitute the basic stuff of our daily academic work: they are the papers, books, software, articles, algorithms, and presentations that we compose and digest. These uses of language position us in a social field as a scholar, a consultant, a change agent, etc., and thus continually enact and constitute our identities. Our projections of understanding about the world and about our identity in that world are within this specific form of life, In our case, it is a form of life that involves socio-technical assemblages of computers, networks, people, applications, organizations, representations, and practices of informing (Boland and O'Leary 1991), as well as our role in both shaping and reflecting upon these socio-technical worlds.

Our uses of language and the understandings we create are not innocent. Instead, by engaging in our form of life, we not only construct our identity and position in the field, but we also trigger identity transformations in the subjects that we study. Hence, the process of identity formation is ubiquitous and inevitable. All we ask is that researchers recognize and take responsibility for critical moments of identity formation in the discourse that shapes the information systems field. We do this through the reflexive monitoring of conduct that is the central dynamic of structuration. By attending to our reflective monitoring of conduct, we shift our attention from asking what things 
we should be, or be aligned with, to asking how we are becoming who we are through our discourse moves.

Our language games are both the medium and outcome of our research practice, and our scholarly work is an identity constructing enterprise-a design project. By engaging in the design of ourselves and the world through our research, we build an identity of who we and our subjects are and might be. The ongoing flow of observing, interviewing, surveying, programming, and experimenting in our research work draws upon and shapes both our own identities as researchers and the identity of our research subject. Hence, one way forward in doing information systems research and constructing the identity of the field is to avoid static thinking of what our theories, methods, or objects of study should be, and to instead reflexively and critically engage in the social construction of ourselves, our field, and our object of study. Next we discuss how we can use some of Giddens' (1984) concepts of structuration theory to engage in this process.

\section{INFORMATION SYSTEMS RESEARCH AS AN ONGOING PROCESS OF STRUCTURING THE INFORMATION SYSTEMS FIELD}

We are not committed to structuration theory as true believers of it. Yet, we do find that Giddens' (1984) modes of structuration offer helpful ways of classifying and thinking about how information systems researchers become active designers of both selves and of a socio-technical world (see Figure 1).

Empirical research, as traditionally conceived, can be defined as the practice of observing and intervening into information systems as they are, through a theory-based inquiry that draws upon modes of signification created and made available in our information systems research practice (bold arrow 5). Constructive information systems research (Madnick 1995; March and Smith 1995; Nunamaker et al. 1991), on the other hand, can be defined as the practice of observing current practice (arrow 5), imaging and building novel technical artifacts based on information and computational theories (arrow 2) that offer new capabilities (resources) and ways of thinking about organizational computing (signification structures). The role of our research in constituting these structures which we draw upon in our observations and interventions is evident (arrow 2): we utilize and quote earlier theories and artifacts that we have learned, built, and internalized as well as the words and concepts passed on by our ancestors; we use software packages and instruments (resources) that are critical in our data collection and analysis or design practice; and we subjugate ourselves to the norms and expectations of good academic citizenship by following rules ofblind refereeing, pro bono reviewing, and avoidance of plagiarism. These structures are enforced and enacted in our every day work as academic citizens as shown through the cycle produced through arrows 1 and 2.

All information systems research practice simultaneously constitutes a design practice to the extent it becomes an activity that creates over time new modes of signification, new modes of power (resources), and new modes of legitimation in the socio-technical world of information systems practice. This happens either directly by designing and transferring technology artifacts and solutions that are appropriated in practice through technology transfer, or indirectly by formulating new signification structures or modes of legitimation 


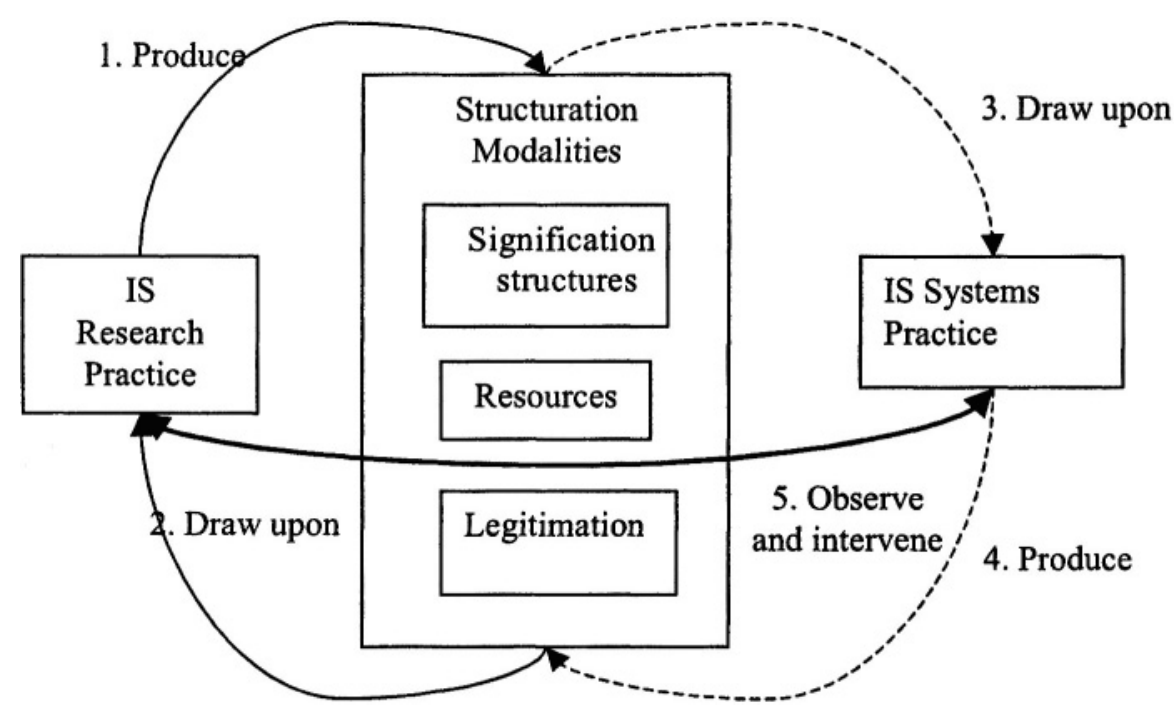

Figure 1. Structuration Processes and Information Systems Research

that are adopted in practice. This process of designing the world through continuous Structuration of the social and technical field is depicted by arrows 1 and 3 in Figure 1. Stocks of signification structures, new computing and design resources, and new legitimation modes produced in information systems discourse may become actively drawn upon in information system practice through the processes of learning, appropriation, and adoption. ${ }^{1}$ We emphasize the word may because actors in information systems practice normally draw upon a large number of different modes of signification and resources, and therefore the link between research outcomes and transformed information systems practice is not fixed or deterministic. In contrast, it may demand engagements in various types of knowledge creation and transformation networks that do the Structuration work. Many of these are fragile and currently poorly understood (Klein and Lyytinen 2003).

Academic research practice is, in turn, central to establishing our role as designers of the socio-technical world in multiple ways. First, our discourses both draw upon (arrow 4) and reinforce (arrows 2 and 3) conventional sets of computational resources, but they also create powerful new immutable mobiles of resources that are appropriated and drawn upon in practice. These resources may sometimes become so powerful as to reconstitute or transform large parts of information systems practice. The invention of CASE tools, ERP systems, and collaborative tools within our discourse is a case in point. Second, academic research practice also establishes our role as designers indirectly in that we are always designing the symbols circulating in our social field (arrows

${ }^{1}$ To clarify the different ways in which modalities of structuration are drawn upon and made available, we use different types of arrows to distinguish the duality of structure in research discourse from that of informations system practice. 
1 and 2). We as scholars explore existing modes of signification and transfer them to other parts of information systems practice, thereby transforming or reinforcing them. At some rare moments, if we are lucky, we may invent new modes of signification, thus giving new meanings to old practices or creating new practices that open wholly new socio-technical worlds to explore. When this happens, the terms of our research become the terms in which managers and information systems practitioners come to see and discuss their own organizational lives in the context of the socio-technical projects in which they are engaged. Similarly, assumptions of power and its possibilities for being exercised are being inhibited or encouraged by the continual design and invention of new tools and methods, which offer unprecedented capabilities to shape the behaviors of that socio-technical world. We also design indirectly by highlighting certain sociotechnical organization features and hiding others-by serving some goals and needs in organizations, but overlooking others.

Finally, we cannot and do not conduct our research without exercising values in selecting, operationalizing, and giving order to particular features of a socio-technical landscape, and valuing them in certain ways as effective, appropriate, or harmful, which we then encourage others to take seriously as being real components of their world. Hence, the normative and power implications of our selection of research subjects, theories, and methods are inescapable and make us, both directly and indirectly, designers of the socio-technical world.

The way forward in our research, then, is to become more reflexive about the wake of design artifacts, signifiers, power relations, and norms that we strengthen or weaken in the process of making and reporting our research. This way forward recognizes our identity as scholars that fill the world with new meanings, offer judgments about what is good or bad, effective or not, and endow actors with new powers and capabilities. It is all of these at the same time that defines the identity of an information systems scholar as a designer. Hence, in thinking about the identity of the information systems field, it is critical to recognize the ongoing, multilayered structuration processes through which we design the very same socio-technical world that we study. This is also an identity construction process through language games that shape the forms of life we inhabit as well as of those whom we study. In other words, the thing in itself that we study is not as important as the (structurational) way we study it, because the way we study it brings both it and ourselves into being, and makes them significant.

If we try to study a thing an sich, ${ }^{2}$ we are endlessly caught up in debates about what the true shape, qualities, and characteristics of the thing are, and how it is different from other things. If we accept that our research is a design project, and that the quality of our work and construction of our identity is found in that process of design in which structurational elements of power (resources), meaning (signification modes), and legitimation (norms and values) are shaped for an organizational information systems practice, then we can open a new space for dialogue in exploring our normative positions as designers - a space in which movement that appreciates both the accomplishments of the past and the creation of new possibilities is valued. Similarly, if we accept that the research space we create provides a set of structurational elements to the

\footnotetext{
${ }^{2}$ An sich-the thing-in-itself.
} 
very subjects we study for their own practices and identity, our focus turns from studying them as things or objects to enabling their identity construction by providing them a stimulating field of values and norms, a potent vocabulary, and new resources with which to play.

\section{INFORMATION SYSTEMS RESEARCH IDENTITY AS A NARRATIVE}

Identity as a process, for ourselves as researchers, for technologies, and for organizations and their actors, is largely constructed through the narratives of the language games in which we participate. As noted, we establish ourselves as powerful and significant agents in the double-hermeneutics of the socio-technical world we design: we build meta-narratives (arrow 1) of the narratives that are available in the world (arrows 2 and 4), and already full of meaning. But our meta-narratives also enter that world as texts (arrow 3) and thereby affect the way in which meaning and understanding emerges in that world. We as researchers punctuate the stream of our life experience into scripts of events in which both social and technical agents of all kinds, with motivations and causal powers, play out specific strategies (Callon 1992; Latour 1993, 1996; Law 1992). The narratives we make of our experience with these heterogeneous networks of artifacts and humans makes things sensible to us and also to those we study.

Narratives have a beginning, middle, and end, which we as narrators keep in motion. A story begins when confusion arises about the world we engage and project in our designs. The story then tells about our struggle to make the world more intelligible, or more desirable. The story ends with our victory (or loss) and with new vocabulary elements that are subsequently entered into the broader discourses of the socio-technical world. In the beginning of the story, there is an order to a situation. That order is disturbed and finally restored or reconceived at the end-either claiming a success or failure (a tragedy) for the system. It is not just researchers, but also managers, clients, and customers who are constructing understandings of self and navigating organizational space by making sense of their flow of experience within similar narrative structures. Those narratives often take the form of a journey, in which they face hardships, overcome obstacles, suffer defeats, receive assistance, and seek a purpose. In our subjects' identity construction process, our research (meta)narratives become part of their organizational/technological narratives, or at least become a part of the narrative space in which they make sense of their experience. The plot and moral of our stories are not written into them, but read into them in a process which Bruner (1990) refers to as subjunctive. When we tell a story to ourselves, or as we hear a story being told, we are always also "reading between the lines" and inferring its meanings, intentions, plots, and significance for ourselves.

In our narratives we are trapped by our subjunctive power and the modes of signification that are re-created and drawn upon in these narratives. If we choose to make our research more relevant and realistic, we risk reinforcing the narratives that already structure organizational life in postmodern society, thereby subsuming ourselves within existing stories and worlds. If we chronicle a narrative that tells a different story 
of the future or negates the world as it is, we face the risk of not being read and of pitting ourselves against a powerful, dominant narrative, thereby marginalizing ourselves as designers. If we choose the narrative of a highly specialized and abstract theory, we risk that its appropriation is difficult and its value for providing meaning for action becomes questioned so that no subjunctive power can be applied to it. This leaves our designs lifeless and devoid of passion. Finally, if we choose to align ourselves with a particular research tradition and its ways ofunderstanding the world, we are reinforcing its struggle to become a dominant narrative, thereby excluding other design possibilities. In following any of these paths, we are relinquishing our own identity construction to a residue of the past - as found in the sedimented layers of social practices or research traditions that we happen to be attending to at any given moment.

For instance, we may reinforce the narrative of organization as sentient being with values that shape its reasoned course of action, or we may reinforce a narrative of humans and organizations as information processing systems, or we may reinforce the narrative that technologies and tools are the central feature in a design solution, but in any case we run the risk of losing our own identity by serving the structurational narratives of another. As a researcher-designer we should ask if a particular information processing view (contingency, transaction cost, resource based, etc.) or organizational narrative (beneficent parent, rogue pirate, abusive spouse, etc.) is useful to us or our readers in how we want to engage in design. The adoption of others' narratives is both powerful and dangerous. We should realize that adopting any one of them is appropriate only if done in moderation and with a sense of irony, even though at the same time we are taking it seriously in the reflexive monitoring of our own conduct. Again, our responsibility as reflexive designers is to keep the stock of our signification structures and legitimation devices in motion - by sometimes following a strong current in one direction and allowing it to carry us along with curiosity as to where it will lead, and sometimes working against that current, to establish our own voice and an alternative branch of thought. This keeps the design scope of our research open to the world. The choice of when to allow the current narrative or our pet theory to carry us along and when to resist it and work against it is an existential, design choice and is the critical moment of how we create an identity as reflexive researchers and designers.

As Wittgenstein (1953) writes, we are always "bewitched" by the vocabulary of concepts, images, and narratives of our research that we cannot escape. The only hope we have in overcoming the illusions and blindness of our language is what Wittgenstein offers us: to understand both the limits and the traps of any language and its vocabulary. Yet, our and others' ability to make sense of a stream of experience and to act at all depends upon that same vocabulary. We cannot speak without it. We can only think within it and we can only act through it. But our vocabulary does change, and we can make changes to it through reflexivity and by being critical toward it, by acting on it, and by pushing it toward its limits (into a new structuration space). Never all at once, but piece by piece, we can and do reconstruct and deconstruct our vocabulary and thereby our identity and our world through simultaneously designing and learning about it. This forms an important critical goal (norm) for us as information systems researchers qua designers - a productive reshaping of our vocabulary driven by a dialogue of assimilation and accommodation, ofdialectic tensions, and of structural oppositions within our forms of life, all within narratives of moving forward on a journey of self discovery in 
designing our socio-technical world. In short, we cannot escape our vocabulary, but we can and must resist it if are to act as designers at all. Perhaps resisting our received vocabulary is necessary to make research a fully human endeavor, which helps us keep our identities consistent yet living and continually changing. Only in this way can we overcome the traps of thingness in building up our identity where we close our language and reflect a given and fixed world and thereby become forever bewitched by just one vocabulary that we admire or endorse.

\section{AN ILLUSTRATIVE CASE STUDY OF REFLEXIVE MONITORING OF IS RESEARCH AND CONSTRUCTION OF OUR IDENTITIES}

By way ofexample and to clarify the concepts of language games, structuration, and narrative in a concrete research context we shall discuss our situation in a research project we have recently begun. Our project studies the impacts of using three-dimensional digital representation technologies in architecture and construction. These technologies are the result of significant research and design that developed computational methods for managing, rendering, and manipulating 3D representations that simulate buildings (or any other physical object). We have initially conceived the adoption and use of these technologies as a path creation process whereby multiple actors across different communities of practice engage in deviant and innovative work processes using such representational capabilities (qua resources) in designing and constructing a building. Our assumption is to view this as an active re-creation, destruction, and modification of legitmation, signification, and power structures through which architectural and construction agency is exercised due to the availability of new representational and computational technologies. These technologies of representation embed new information about construction objects and their features, reshaping the way in which a building is conceived, represented, and analyzed. In particular, we are interested in how Frank Gehry's architectural practice has been affected by the exploitation of such software capabilities and how it has changed the language of his architecture and the resources and legitimation structures that need to be mobilized to construct his buildings.

As part of our engagement in this project we recently received a letter from a well established architect who has worked in Gehry's office for over 10 years and who is very knowledgeable of the state of the architectural design and of the ideas that underlie the agency of being an architect. In this letter he said in part,

What I personally find interesting about your research is that you are resurrecting the status of architecture as an instrument of knowledge. I think that's a marvelous side effect. You are reestablishing the position and weight of architecture that architecture once held in the world... (Fineout 2003).

Our research project may or may not succeed in the domain of journal publication or in achieving the noble goal of restoring architects as master builders, but while writing this essay we recognized that our project is not just an innocent intervention that 
follows the cycle of observation-theory building- and validation (shown in Figure 1), but, in addition, it inevitably involves a process of identity construction for both our subjects and ourselves (through circulating across all paths in Figure 1). Hence, we have become designers of the socio-technical world unknowingly by engaging in this project. This particular subject happened to recognize it immediately as he had struggled for a while with his relationship between agency and representation in architecture. Many other research subjects may not realize it as easily, including ourselves until we started to write this essay and read Fineout's letter again.

If we analyze our research project in light of Figure 1, we can observe the following. First by embarking on this project we are redefining ourselves as information system scholars by beginning to study something that is not a part of information systems research as it is currently conceived, and thus expanding its signification structures to topics and theories that previously were not part of our identity. We are not studying how to manage technology resources, or how to align strategies of architects' offices or constructors with specific new technological capabilities. We are also not interested in specific attributed causal impacts between 3D technology adoption (your favorite TAM version) and its organizational impacts (like work satisfaction, profitability, centralization, etc.). Instead our primary focus is to understand how 3D technologies as developed in one domain (aerospace industry) become serendipitously adopted within another industry (architecture and construction) and how this adoption is driven by specific dreams of what it means to be an architect and what structures such agency draws upon during this transformation process.

By studying the process of constructing a new architectural agency through new means of representation, and the new resources that come with it, we also establish a new understanding of our identity as information system researchers. We enter as a new agency into the field of construction and architectural practice by offering concepts, theories, and models which different actors in that field can use to make sense of and narrate their activity differently, and thereby learn to deconstruct and reconstruct their identity.

This is not a painless process and throughout our interventions and interviews we have learned how multiple contractors engaging in 3D-based construction projects have struggled to redefine their identity: how craftsmen have changed their skill sets and capabilities to become competent users of 3D representations, how roles and responsibilities of workgroups and trades have become renegotiated, and how we have made them narrate their experience in light of the (meta)narratives that guide our storytelling. ${ }^{3}$ Later, we might offer new theoretical concepts, models, and language to talk about and build agency in architecture and construction. If we offer new resources that can be appropriated, and articulate new values or norms that emerge from discussions of what good construction and architecture means, we may become even more deeply involved in the design of the socio-technical world of 3D technologies in architecture and construction.

${ }^{3}$ These include theories of information processing, actor network theory, distributed cognition and knowledge sharing, organizational learning, and economics of knowledge and production networks. 


\section{IMPLICATIONS}

What are the implications of this view of information systems research that emphasizes its constitutive process of design over its outcomes as our major concern? We propose that there is an implication for balance, which calls for both a heightened resistance, and for heightened responsibility. First, sensitivity to balance opens us to a deconstructive questioning of what is too well represented and what is not represented well enough in our research, theories, methods, and subjects. Our activities as designers can easily result in blind spots and aspects in the world that we do not engage and thereby silence. For instance, the way information systems research (except for certain socio-technical studies) has ignored labor is distressing, despite early attempts by Scandinavian researchers (see, for example, Ehn 1988; Sandberg 1985). We seem to act as if information and intelligence are solely the province of managers and knowledge workers. We act as if craftsmen (machinists, tool and die makers, sheet metal workers, plumbers, electricians, painters, carpenters, etc.) do not use information with intelligence and do not create knowledge in ways that are just as important, if not more important, than software designers, marketing directors, or plant managers. Labor is powerfully involved in the construction and use of the socio-technical world, and is a peculiar blind spot in our research, which we should resist.

Second, for us as researchers and designers, the question becomes: How do we structure our research space to overcome imbalances in the ways we constitute our research subjects and subsequently shape the socio-technical world? Do we seek a full, vibrant, dynamic space in which boundaries are stretched in multiple directions, favorite vocabularies are alternately strengthened and challenged, familiar situations are renarrativized as exotic, and a sense of playfulness keeps our work ironic and surprising? We should continuously ask: What kinds of organizational and technological space are we creating for the subjects of our research and for society at large? Again, the problem is to resist the default path of searching for things in the form of theories, models, and tools, and instead seek a richer vocabulary of images, concepts, and narratives that can enable us and our research subjects to reflexively engage in design and create more desirable states of affairs.

Third, we have to be prepared for unavoidable struggle that follows from seeking the balance: within any one theory or method, we have a problem of needing to both believe and not believe in it - to both live in a tradition and to overcome it (Gadamer 1975). The seeking of balance is never simple or straightforward. Balance comes from both strengthening a position and from challenging it, from pushing work further in one area as well as from opening new horizons and proposing new questions to address. What will give balance in a situation is always dependent on an interpretive act within a tradition which comes down to what (meta)narratives we follow and believe and how we subjugate to them. Hence, we are back to our earlier assertion that we always face an existential choice in creating our research, our identity, and the identity of our research subject.

Fourth, seeing information systems research as a process of social construction and structuration may lead some to conclude that we are resigned to complete relativism and are giving up the foundations of a rational base for doing research. Aren't we also 
negating the value of theories and rigor in conducting research if any narrative can be deployed and mobilized in information system practice? We deny such allegations as the power of our research agency comes exactly from the specific sets of resources, signification structures, and legitimation modes that are drawn upon and recreated in our research practice. Moreover, these structures are always reflexively monitored (we are doing it just now!) through the signification structures and legitimation modes in which such concepts as rigor, theory-based, causality, and validity are embedded within our discourses and are mobilized to weave specific (meta) narratives. The modalities of signification that we employ continually redefine our identity and our position in the field - they are not separate from who we are as information system researchers, and should be the result of justified and authentically informed existential choices that we and our ancestors have made.

Finally, and most importantly, the challenge we pose in this essay is that not making existential choice a part of our reflexive awareness leaves us as inauthentic, passive observers of the world. It confines us to be researchers who pretend that there are firm foundations for a preferred theory and method to study a world given as a set of things, a preferred research object, and a preferred identity for ourselves. But, as we argue, there is no such foundation and a realization of that is just what has made us flounder over the last years as we came to value the pluralistic and relatively open space of discourse we find ourselves in today. To fix our identity into a specific set of relationships with specific things would be a step back into history. Yet, to move forward in that new space with no foundation and no boundaries is a problem that leads us to ask what is our identity, what is consistent and stable?

In this paper we suggest that our identity lies in the consistency of the fundamental processes in which we engage as designers. This demands that we reflexively embrace responsibility for the existential moments of choice which give rise to our narratives of self and other; the theories, methods, and subjects those stories embody; and our continuing process of constructing identity for self and others. These choices are the medium and outcome of our form of discourse and engagement with them is our unavoidable fate.

\section{REFERENCES}

Apel, K. Towards a Transformation of Philosophy, London: Routledge and Kegan Paul, 1980 Baskerville, R., and Myers, M. "Information Systems as a Reference Discipline," MIS Quarterly (26:1), 2002, pp. 1-14.

Benbasat, I., and Weber, R. "Research Commentary: Rethinking 'Diversity' in Information Systems Research,” Information Systems Research (7:4), 1996, pp. 389-399

Benbasat, I., and Zmud, R. "The Identity Crisis Within the IS Discipline: Defining and Communicating the Disciplines's Core Properties, MIS Quarterly (27:2), 2003, pp. 183-194.

Boland, R. "Phenomenology: A Preferred Approach to Research in Information Systems," in E Mumford, R. Hirschheim, G. Fitzgerald, and A. T. Wood-Harper(Eds.), Research Methods in Information Systems, Amsterdam: North-Holland, 1985, pp. 193-203.

Boland, R., and O'Leary, T. "Technologies of Inscribing and Organizing: Emerging Research Agendas," Accounting, Management and Information Technologies (1:1), 1991, pp. 1-7.

Bruner, J. Acts of Meaning, Boston: Harvard University Press, 1990. 
Callon, M. "The Dynamics of Techno-Economic Networks," in R. Coombs, P. Savotti, and V. Walsh (Eds.), Technological Change and Company Strategies: Economic and Sociological Perspectives, San Diego: Harcourt Brace Jovanovich, Publishers, 1992.

Deetz, S. "Describing Differences in Approaches to Organization Science: Rethinking Burrell and Morgan and Their Legacy," Organization Science (7:2), 1996, pp. 191-207

Ehn, P. Work-Oriented Design of Computer Artifacts, Ph.D. Dissertation, Stockholm: Arbetslivscentrum, 1988.

Fineout, M. Private communication to Richard Boland and Kalle Lyytinen, February 22, 2003.

Gadamer, H.-G. Truth and Method, G. Barden and J. Cumming, Trans., New York: Seabury Press, 1975.

Giddens, A. The Constitution of Society, Cambridge, MA: Polity Press, 1984.

Jenkins, A. M. "Research Methodologies and MIS Research," in E Mumford, R. Hirschheim, G. Fitzgerald, and A. T. Wood-Harper (Eds.), Research Methods in Information Systems, Amsterdam: North-Holland, 1985, pp. 25-47.

Landry, M., and Banville, C. "Disciplined Methodological Pluralism for MIS Research," Accounting, Management and Information Technologies (2:2), 1992, pp. 77-97.

Klein, H., and Lyytinen, K. "The Powerty of Scientism in Information Systems," in E. Mumford, R. Hirschheim, G. Fitzgerald, and A. T. Wood-Harper (Eds.), Research Methods in Information Systems, Amsterdam: North-Holland, 1985, pp. 131-162.

Klein, H., and Lyytinen, K. "Knowledge Creation and Transformation in Networks: The Case of Relevancy of IS Research," unpublished working paper, Weatherhead School of Management, Case Western Reserve University, 2003.

Latour, B. "Ethnography of a 'High-Tech' Case: About Aramis," in P. Lemannier (Ed.), Technological Choices: Transformations in Material Culture Since the Neolithic, London: Routledge and Kegan Paul, 1993.

Latour, B. Science in Action: How to Follow Engineers and Scientists Through the Society, Boston: Harvard University Press, 1992.

Latour, B. "Social Theory and the Study of Computerized Work Sites," in W. J. Orlikowski, G. Walsham, M. R. Jones, and J. I. DeGross (Eds.), Information Technology and Change in Organizational Work, London: Chapman \& Hall, 1996, pp. 295-307.

Law, J. "Notes on the Theory of the Actor-Network: Ordering, Strategy, and Heterogenity," System Practice (5:4), 1992, pp. 379-393.

Lee, A. S., Liebenau J., and DeGross J. I. (Eds.). Information Systems and Qualitative Research, London: Chapman \& Hall, 1997

Lyytinen, K., and Klein, H. "Critical Social Theory of Jurgen Habermas (CST) as a Basis for the Theory of Information Systems," in E. Mumford, R. Hirschheim, G. Fitzgerald, and A. T. Wood-Harper (Eds.), Research Methods in Information Systems, Amsterdam: NorthHolland, 1985, pp. 219-236.

Madnick, S. "Information Technology: The Reinvention of the Linkage between Information Systems and Computer Science," Decision Support Systems (13:4), 1995, pp. 373-380

March, S., and Smith, G. "Design and Natural Science Research in Information Technology," Decision Support Systems (13:4), 1995, pp. 251-266

Mingers, J. "Combining IS Research Methods: Towards a Pluralist Methodology," Information Systems Research (2:3), September 2001, pp. 240-259

Mumford, E.; Hirschheim, R., Fitzgerald, G.; and Wood-Harper, A. T. (Eds.). Research Methods in Information Systems, Amsterdam: North-Holland, 1985.

Nissen, K-E.; Klein, H.; and Hirschheim, R. (Eds.). Information Systems Research: Contemporary Approaches and Emergent Traditions, Amsterdam: North-Holland, 1991.

Nunamaker, J.; Chen, M.; and Purdin, T. "Systems Development in Information Systems Research," Journal of Management Information Systems (7:3), 1991, pp. 89-106. 
Orlikowski, W. J., and Iacono, C. S. "Desperately Seeking the 'IT' in IT Research-A Call to Theorizing the IT Artifact," Information Systems Research (12:2), June 2001, pp. 121 -134. Pitkin, H. F. Wittgenstein andJustice, Berkeley, CA: University of California Press, 1972. Robey, D. "Diversity in Information Systems Research: Threat, Promise and Responsibility," Information Systems Research (7:4), 1996, pp. 400-408.

Sandberg, A. "Socio-Technical Design, Trade Union Strategies and Action Research," in E. Mumford, R. Hirschheim, G. Fitzgerald, and A. T. Wood-Harper (Eds.), Research Methods in Information Systems, Amsterdam: North-Holland, 1985, pp. 79-92.

Simon, H. The Sciences of the Artificial ( $3^{\text {rd }}$ ed.), Boston: MIT Press, 1996.

Suchman, L. "Organizing Alignment: A Case of Bridge-Building," Organization (7:2), 2000, pp. 311-327.

Weber, R. "Editor's Comments: Still Desperately Seeking the IT Artifact," MIS Quarterly (27:2), pp. iii-xi.

Wittgenstein, L. Philosophical Investigations, Oxford: Blackwell, 1953.

\section{ABOUT THE AUTHORS}

Richard J. Boland, Jr. is a professor of Information Systems at the Weatherhead School of Management, Case Western Reserve University. Previously he was Professor of Accountancy at the University of Illinois at Urbana-Champaign. He has held a number of visiting positions, including the Eric Malmsten Professorship at the University of Gothenburg in Sweden in 198889, and the Arthur Andersen Distinguished Visiting Fellow at the Judge Institute of Management Studies at the University of Cambridge in 1995. His major area of research is the qualitative study of the design and use of information systems. Recent papers have concerned sense making in distributed cognition, hermeneutics applied to organizational texts, and narrative as a mode of cognition. Richard was founding editor of the research journal Accounting, Management and Information Technologies (now Information and Organization) and is coeditor of the Wiley Series in Information Systems. He serves on the editorial Board of six journals, including Accounting, Organizations and Society. His most recent book is Managing as Designing (Stanford University Press, 2004) coedited with Fred Collopy. He can be reached at Boland@Case.edu.

Kalle Lyytinen is Iris S. Wolstein Professor in the Department of Information Systems at Case Western Reserve University and an adjunct professor at the University of Jyväskylä, Finland. He serves currently on the editorial boards of several leading IS journals including Journal of the AIS, Information Systems Research, Information \& Organization, Requirements Engineering Journal, and Information Systems Journal. He has published over 150 scientific articles and conference papers and edited or written eight books on topics related to system design, method engineering, implementation, software risk assessment, computer supported cooperative work, standardization, and ubiquitous computing. He is the former chairman of IFIP 8.2. and was one of the original contributors to the proceedings of the conference in 1985. His research interests include information system theories and research methods, computer-aided system design and method engineering, system failures and risk assessment, computer supported cooperative work and nomadic computing, and the innovation and diffusion of complex technologies and the role of institutions in such processes. Kalle can be reached at kj113@cwru.edu. 